tent and in what directions the authors of these produsts of an "infant industry" may be expected to develop. Let us hope that some one will undertake the task.

Coldmbia College, January, 1884.

E. M. BLAKE.

\title{
THE TEACHING OF MATHEMATICS IN THE SECONDARY SCHOOLS.
}

FXTRACT FROM THE REPORT RENDERED TO THE NATIONAL EDUCATIONAL SOCIETY, DECEMBER 4, 1898, BY THE COMMITTEE ON SECONDARY SCHOOL STUDIES.*

At the meeting of the National Educational Association held in Saratoga, July 9, 1892, a committee of ten was appointed to organize a series of conferences upon the subjects and methods of instruction in the secondary schools and to prepare a report based upon the results thus obtained. The members of this committee were: Charles W. Eliot, President of Harvard University, Cambridge, Mass., Chairman; Willfam T. Harris, Commissioner of Education, Washington, D. C.; James B. Angell, President of the University of Michigan, Ann Arbor, Mich.; Johu. Tetlow, Head Master of the Girls' High School and the Girls' Latin School, Boston, Mass.; James M. Taylor, President of Vassar College. Poughkeepsie, N. Y.; Oscar D. Robinson, Principal of the High School, Albany, N. Y.; James H. Baker, President of the University of Colorado, Boulder, Colo.; Richurd H. Jesse, President of the University of Missouri, Columbir, Mo.; James C. Mackenzie, Hend Muster of the Lawrenceville School, Lawrenceville, N. J.; Henry C. King, Professor in Oberlin College, Oberlin, Ohio.

The persons selected by them to hold the conference upon mathematical studies were the following: Professor William E. Byerly, Harvard University, Cambridge. Mass ; Professor Florian Cajori, Colorado College, Colorado Springs, Colo.: Arthur H. Cutler, Principal of a Private Bchool for Boys, New York City; Professor Henry B. Fine, Oollege of New Jersey, Princeton, N. J.; W. A. Greeson, Principal of the High School, Grand Rapids, Mich.: Andiew Ingraham, Bwain Free Schnol, New Bedford, Mass.; Professor Simon Newcomb, Johns Hopkins University, and Washington, D. C.: Professor George D. Olds, Amherst College, Amherst, Mass.; James L. Patterson, Lawrenceville School, Lawrenceville, N. J.; Professor T. H. Safford, Williams College, Willianstown, Mass.

We reproduce below the remarks of the committee in regard to the report of the mathematical conference. The report of the committee, with the reports of the several conferences appended, may be obtained fron the U. S. Bureau of Education upon application.-EDirors.

THE form of the report of the Conference on Mathematicst differs somewhat from that of the other reports. This report is subdivided under five headings : 1st, General Conclusions. 2d, The Teaching of Arithmetic. 3d, The Teaching of

* U. S. Bureau of Education, Circular No. 205 (1893), 8vo, 249 pp.

† lbid., pp. 104-116. 
Concrete Geometry. 4th, The Teaching of Algebra. 5th, The Teaching of Formal or Demonstrative Geometry.

The first general conclusion of the Conference was arrived at unanimously. The Conference consisted of one government official and nniversity professor, five professors of mathematics in as many colleges, one principal of a high school, two teachers of mathematics in endowed schools, and one proprietor of a private school for boys. The professional experience of these gentlemen and their several fields of work were various, and they came from widely separated parts of the country; yet they were unanimously of opinion "that a radical change in the teaching of arithmetic was necessary." 'They recommend "that the course in arithmetic be at once abridged and enriched; abridged by omitting entirely those subjects which perplex and exhaust the pupil without affording any really valuable mental discipline, and enriched by a greater number of exercises in simple calculation, and in the solution of concrete problems." They specify in detail the subjects which they think should be curtailed, or entirely omitted ; and they give in their special report on the teaching of arithmetic a full statement of the reasons on which their conclusion is based. They map out a course in arithmetic which, in their judgment, should begin about the age of six years, and be completed at about the thirteenth year of age.

The Conference next recommend that a course of instruction in concrete geometry with numerous exercises be introduced into the grammar schools; and that this instruction should, during the earlier years, be given in connection with drawing. They recommend that the study of systematic algebra should be begun at the age of fourteen; but that, in connection with the study of arithmetic, the pupils should earlier be made familiar with algebraic expressions and symbols, including the method of solving simple equations. "The Conference believe that the study of demonstrative geometry should begin at the end of the first year's study of algebra, and be carried on by the side of algebra for the next two years, occupying about two hours and a half a week." They are also of opinion "that if the introductory course in concrete geometry has been well taught, both plane and solid geometry can be mastered at this time." Most of the improvements in teaching arithmetic which the Conference suggest "can be summed up under the two heads of giving the teaching a more concrete form, and paying more attention to facility and correctness in work. The concrete system should not be confined to principles, but be extended to practical applications in measuring and in physics."

In regard to the teaching of concrete geometry, the Conference urge that while the student's geometrical education 
should begin in the kindergarten, or at the latest in the primary school, systematic instruction in concrete or experimental geometry should begin at about the age of ten for the average student, and should occupy about one school hour a week for at least three years. From the ontset of this course the pupil should be required to express himself verbally as well as by drawing and modelling. He should learn to estimate by the eye, and to measure with some degree of accuracy, lengths, angular magnitudes, and areas; to make accurate plans from his own measurements and estimates; and to make models of simple geometrical solids. The whole work in concrete geometry will connect itself on the one side with the work in arithmetic, and on the other with elementary instruction in physics. With the study of arithmetic is therefore to be intimately associated the study of algebraic signs and forms, of concrete geometry, and of elementary physics. Here is a striking instance of the interlacing of subjects which seems so desirable to every one of the nine Conferences.

Under the head of teaching algebra, the Conference set forth in detail the method of familiarizing the pupil with the use of algebraic language during the study of arithmetic. This part of the report also deals clearly with the question of the time required for the thorough mastery of algebra through quadratic equations. The report on the teaching of demonstrative geometry is a clear and concise statement of the best method of teaching this subject. It insists on the importance of elegance and finish in geometrical demonstration, for the reason that the discipline for which geometricaldemonstration is to be chiefly prized is a discipline in complete, exact, and logical statement. If slovenliness of expression, or awkwardnessof form, is tolerated, this admirable discipline is lost. 'The Conference therefore recommend an abundance of oral exercises in geometry-for which there is no proper substitute-and the rejection of all demonstrations which are not exact and formally perfect. Indeed throughout all the teaching of mathematics the Conference deem it important that great stress be laid by the teacher on accuracy of statement and elegance of form as well as on clear and rigorous reasoning. Another very important recommendation in this part of the report is to be found in the following passage : "As soon as the student has acquired the art of rigorous demonstration, his work should cease to be merely receptive. He should begin to devise constructions and demonstrations for himself. Geometry cannot be mastered by reading the demonstrations of a text-book; and while there is no branch of elementary mathematics in which purely receptive work, if continued too long, may lose its interest more completely, there is also none in which independent work can be made more attractive and stimulating." These 
observations are entirely in accordance with the recent practice of some colleges in setting admission examination papers in geometry which demand of the candidates some capacity to solve new problems, or rather to make new application of familiar principles.

\section{NOTES.}

A regular meeting of the New York Mathematical Sociely was held Saturday afternoon, January 6 , at half-past three o'clock, the vice-president, Dr. G. W. Hill, in the chair. Mr. John Franklin Shields, of the Adelphi Academy, Brook. lyn, having been duly nominated, and being recommended by the council, was elected a member. Dr. Blake made some general remarks in connection with the recently published concluding volume of Lie's "Theory of Transformation Groups," edited by Engel.

The lists of substitution groups published by Professor Cole in the last volume of the BULLETIN (No. \%, pp. 184-190, No. $10, \mathrm{pp} .250-258$ ) have been reprinted in the Quarterly Jour. nal of Mathematics, vol. 26, pp. 372-388, forming part of another article by Professor Cole, viz. "List of the substitution groups of nine letters."

WE have to record the death, on January 1, 1894, of Heinrich $R$. Hertz, professor of physics in the University of Bonn, at the age of thirty-seven years.

'THe professorship of mathematics at Tulane University, vacated through the death of Professor J. L. Cross, has been filled by the appointment of Dr. W. B. Smith, recently of the Missouri State University.

T. S. F.

Professor Florian Cajori's History of Mathematics has just been published by Macmillan \& Co., of New York. The same house announces as in preparation a volume on Hydrostatics, by A. G. Greenhill, and a new edition of Lord Rayleigh's 'Theory of Sound, comprising the whole subject in two volumes; also a volume on Modern Plane Geometry, by $G$. Richardson and A. S. Ramsey, and one on Geometrical Conic Sections, by Charles Smith.

A. $\mathbf{z}$. 